\title{
Active screening for tuberculosis in high- incidence Inuit communities in Canada: a cost-effectiveness analysis
}

\author{
Aashna Uppal MScPH, Ntwali Placide Nsengiyumva MSc, Céline Signor MSc, Frantz Jean-Louis MPH, \\ Marie Rochette MD MSc, Hilda Snowball, Sandra Etok, David Annanack, Julie Ikey, Faiz Ahmad Khan MD MPH, \\ Kevin Schwartzman MD MPH
}

Cite as: CMAJ 2021 November 1;193:E1652-9. doi: 10.1503/cmaj.210447

\begin{abstract}
Background: Active screening for tuberculosis (TB) involves systematic detection of previously undiagnosed TB disease or latent TB infection (LTBI). It may be an important step toward elimination of TB among Inuit in Canada. We aimed to evaluate the cost-effectiveness of community-wide active screening for TB infection and disease in 2 Inuit communities in Nunavik.
\end{abstract}

Methods: We incorporated screening data from the 2 communities into a decision analysis model. We predicted TB-related health outcomes over a 20-year time frame, beginning in 2019. We assessed the cost-effectiveness of active screening in the presence of varying outbreak frequency and intensity. We also considered scenarios involving variation in timing, impact and uptake of screening programs.

Results: Given a single large outbreak in 2019, we estimated that 1 round of active screening reduced TB disease by $13 \%$ (95\% uncertainty range $-3 \%$ to $27 \%)$ and was cost saving compared with no screening, over 20 years. In the presence of simulated large outbreaks every 3 years thereafter, a single round of active screening was cost saving, as was biennial active screening. Compared with a single round, we also determined that biennial active screening reduced TB disease by $59 \%$ ( $95 \%$ uncertainty range $52 \%$ to $63 \%$ ) and was estimated to cost Can $\$ 6430$ (95\% uncertainty range -\$29131 to \$13658 in 2019 Can\$) per additional active TB case prevented. With smaller outbreaks or improved rates of treatment initiation and completion for people with LTBI, we determined that biennial active screening remained reasonably cost-effective compared with no active screening.

Interpretation: Active screening is a potentially cost-saving approach to reducing disease burden in Inuit communities that have frequent TB outbreaks.
$\mathrm{T}$ uberculosis (TB) was the world's deadliest infectious disease in 2019. ${ }^{1}$ The burden of TB is disproportionately borne by vulnerable and marginalized communities, including Canadian Inuit, ${ }^{2}$ where it reflects colonization and persistent socioeconomic inequities. ${ }^{3}$ Overall, Canada has a low incidence of TB (defined as $<10$ cases per 100000 population annually), ${ }^{4}$ with an incidence rate of 4.9 per 100000 in $2017 .{ }^{5}$ However, the overall incidence across Inuit communities was more than 40 -fold higher. ${ }^{5}$ In 2018, Inuit Tapiriit Kanatami (the national representative organization for Inuit in Canada) and the Government of Canada announced their goal to eliminate TB from Inuit regions by $2030 .^{3}$

In 2019, the incidence of TB in Nunavik (in Northern Quebec) was 495 per $100000 .{ }^{6}$ The Nunavik Regional Board of Health and
Social Services (NRBHSS) implemented community-wide active screening for active TB and latent tuberculosis infection (LTBI) in 2 villages where repeated outbreaks were common. Outbreaks are considered to occur when either 2 or more contacts of a person with active TB are also diagnosed with active TB, or 2 or more people who develop active TB within 1 year are epidemiologically linked; 7 the outbreaks in these villages have been much more extensive. ${ }^{8}$ With active screening, people with TB disease may be identified and receive treatment while minimally symptomatic and less contagious. ${ }^{9}$ People with LTBI may be identified and receive treatment before they develop active TB disease. ${ }^{10,11}$ Active screening is most often undertaken when other practices appear insufficient to interrupt transmission and reduce morbidity, and may be particularly relevant in remote settings. ${ }^{12}$ It is 
pertinent to consider the benefits and costs of community-wide screening, within a TB elimination strategy that also addresses underlying health determinants. ${ }^{13,14}$ We used decision analysis modelling to project health outcomes and costs associated with active screening in these villages over a 20-year time frame. Our objectives were to evaluate the cost-effectiveness of the 2019 screening activities and to assess potential cost-effectiveness of future screening.

\section{Methods}

In 2019, the NRBHSS led community-wide active-screening campaigns in Village 1 (population about 1000) and Village 2 (population about 1500). These campaigns targeted anyone who was not already known to have active TB or LTBI, without age restrictions. Consequently, about $60 \%$ of the inhabitants were eligible for screening in Village 1 and about $70 \%$ were eligible in Village 2. People without a history of LTBI and without symptoms suggestive of active TB underwent tuberculin skin testing (TST). People with a TST result of at least $5 \mathrm{~mm}$ or who had a history of LTBI or active TB underwent chest radiography..$^{15}$ The NRBHSS worked with local staff as well as staff flown in to the villages to organize these screening campaigns. Additional details are provided in the Screening campaigns section of Appendix 1, available at www.cmaj.ca/lookup/ doi/10.1503/cmaj.210447/tab-related-content.

To simulate these campaigns, we incorporated summary public health and cost data into a decision analysis model using TreeAge Pro software (2019). Using simulated population cohorts that reflected the inhabitants of these villages, the model predicted TB-related health outcomes: persons with active TB, latent TB infection, and TB-related deaths, over a 20-year time frame, from 2019. The model also predicted direct cost to the health system, including those of managing active and latent TB, and of screening. We considered open cohorts, ${ }^{16}$ and used an annual discount rate of $1.5 \%$ for future outcomes and costs. ${ }^{17}$

Figure 1 shows a simplified depiction of the model structure. We simulated an active screening campaign in 2019 (reflecting the campaigns that had actually occurred). The counterfactual scenario with no active screening shared the same model structure, but with lower probabilities for diagnosis and treatment of TB infection and disease.

We simulated secondary transmission, using observed data. ${ }^{8,18,19}$ We used a ratio of 1.82 secondary active TB cases per index TB case in Village 1, which reflected pooled data from outbreak and nonoutbreak years. ${ }^{18} \mathrm{~A}$ ratio of 0.67 people with new LTBI per index case was used. 8,19 The relatively low number of persons with incident LTBI reflects the high proportion already infected at baseline (48\% in Village 1 and 33\% in Village 2) versus those susceptible to infection (49\% in Village 1 and $66 \%$ in Village 2) (Appendix 1, Supplementary Table S1). During simulated outbreaks, we increased the probabilities of progression, reactivation and transmission as observed in these villages (see the Simulating outbreaks section of Appendix 1 for details).

\section{Epidemiologic parameters}

Epidemiologic parameters fell into 3 categories. The first included parameters related to TB pathogenesis and treatment. ${ }^{20,21}$ These came from published literature. The second category included parameters related to the LTBI or active TB treatment cascade. These parameters came from the Nunavik TB program data ${ }^{22}$ and were vetted by regional experts and community members. Active screening was considered to increase diagnosis and treatment initiation among people with LTBI and to increase diagnosis among people with active TB. ${ }^{22}$ The specific impact of active screening on these parameters reflected program data from both communities in 2019; details are provided in Appendix 1, Supplementary Table S2. The third category included other parameters, such as duration of hospital admission for TB disease. These were informed primarily by local data. ${ }^{18}$ Table 1 outlines key epidemiologic parameters and their data sources.

\section{Cost parameters}

All costs were considered from the perspective of the health system and adjusted to 2019 Canadian dollars. ${ }^{27}$ Cost inputs fell into 2 categories. The first category included costs related to active screening. These costs came from the Nunavik program data and reflected the steps needed to conduct active-screening activities in both communities in 2019. ${ }^{22}$ All screening campaign costs were incurred by the health system, including lodging and transportation costs for staff who had to be flown into the villages. The second category included costs related to standard TB care. Wherever possible, these costs came from Nunavik, or Nunavut when necessary. Where such information was unavailable, costs came from published literature but were confirmed with regional experts. Table 2 highlights key cost parameters, which are further described in Appendix 1, Supplementary Table S1.

\section{Screening strategies}

We simulated 3 screening strategies, given a single outbreak in 2019, with no subsequent outbreaks.

\section{No active screening (Strategy $A$ )}

We estimated what most likely would have occurred had no active screening been introduced in 2019. We used background rates of diagnosis, treatment initiation and treatment completion for TB disease and LTBI, informed by community data during 2017 and 2018, when there was no active screening. Screening close contacts of persons with TB disease is standard practice.

\section{Community-wide active screening in 2019 only (Strategy B)}

Village 1 and Village 2 had active community-based screening programs in 2019. This strategy incorporated program data to reflect increased rates of diagnosis, treatment initiation and treatment completion compared with Strategy A.

We then simulated an outbreak in 2019 and every 3 years thereafter, because these villages have had TB outbreaks every 2-3 years since $2011 .{ }^{18}$ We considered an additional strategy in this context. 


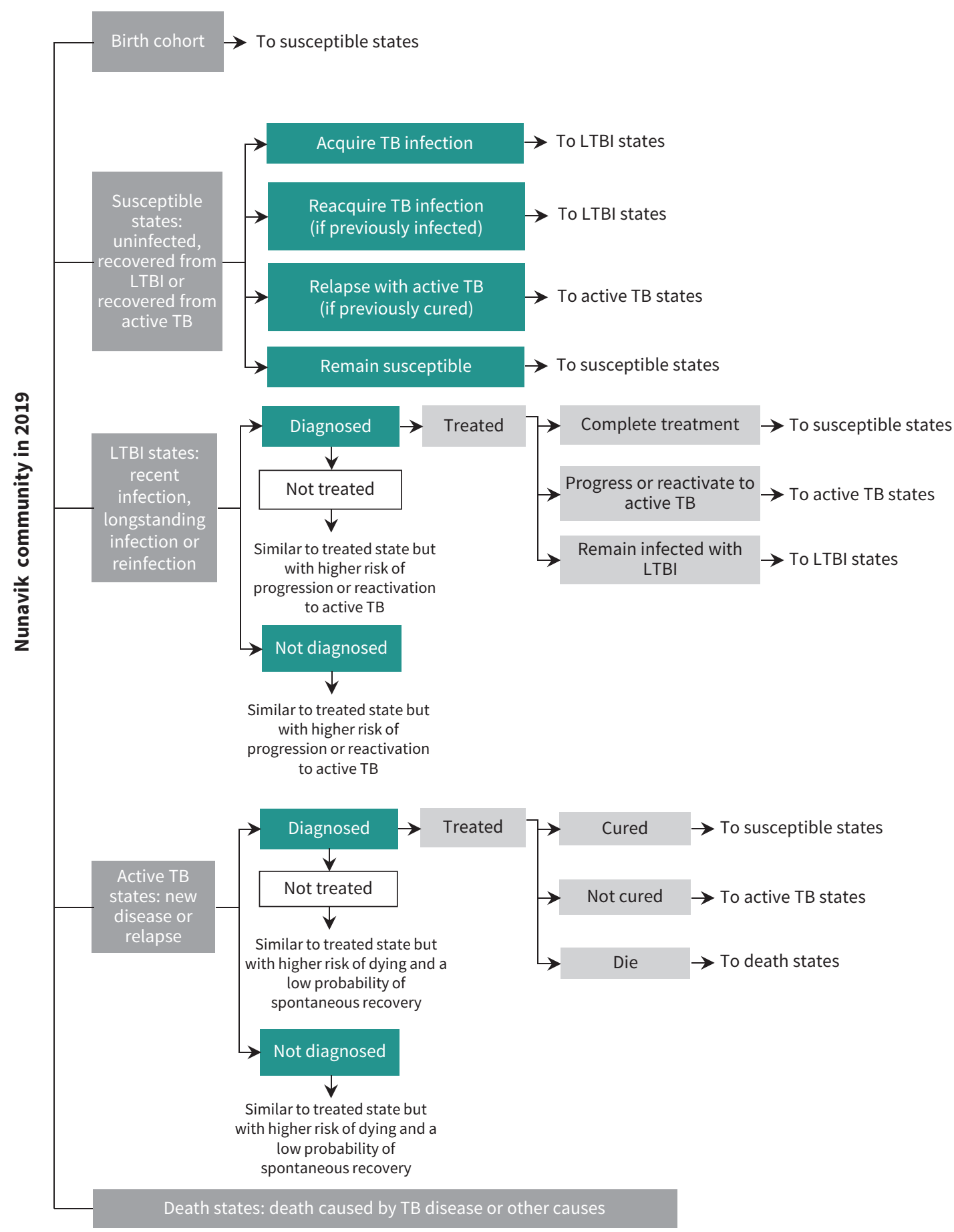

Figure 1: Simplified depiction of the decision analysis model. Transitions between health states are experienced by cohort members in each cycle. For example, each cycle, a number of newborns enter the susceptible states. Here, they may acquire or reacquire infection, relapse with active tuberculosis (TB), or remain susceptible. If infected or reinfected, cohort members move to the latent tuberculosis infection (LTBI) states, where the clinical pathway entails diagnosis and treatment. Probabilities of diagnosis and treatment are lower in strategies where there is no active screening. The clinical pathway for active TB states resembles that of LTBI states. Similarly, probabilities of diagnosis and treatment are lower in strategies where there is no active screening. Finally, there are death states, which include death caused by TB or other causes (i.e., background mortality).

\section{Community-wide active screening every 2 years for 20 years} (Strategy C)

Local public health authorities did not think annual screening was feasible but wished to consider biennial screening.

\section{Secondary analyses}

We considered additional strategies, involving variations in screening frequency and target groups. We also considered several scenarios to explore variations in key model parameters: increased 


\section{Related to TB pathogenesis}

Probability of progression to active TB after recent infection

Probability of reactivation to active TB after remote infection

Annual risk of infection

Probability of cure after complete active TB treatment

Probability of cure after complete LTBI treatment

Probability of dying of untreated TB if smear was negative

Probability of dying of untreated TB if smear was positive

Probability of adverse event during active TB treatment

Probability of adverse event during LTBI treatment

Average number of new LTBI per index TB case

Average number of secondary active TB cases per index TB case

\section{Other}

Annual birth rate

Probability of non-TB-related death (background mortality)

Number of days in hospital if smear was negative*

Number of days in hospital if smear was positive*

\section{TB cascade parameters in the absence of active screening $†$}

Active TB

Proportion of people with active TB who were diagnosed

Proportion of people who were diagnosed and started treatment

Proportion of people who started treatment and completed it

LTBI

Proportion of people with LTBI who were diagnosed

Proportion of people who were diagnosed and started treatment

Proportion of people who started treatment and completed it
$0.05-0.265 \ddagger$

$0.0005-0.075 \ddagger$

0.0095

0.928

0.9

0.02

0.07

0.051

0.003

0.67

1.82

$0.019-0.023 \S$

$0.014-0.021 \S$

14

60

0.829

1

0.99

0.839

0.709

0.75
N'Diaye et al. ${ }^{13}$

N'Diaye et al., ${ }^{13}$ Behr et al. ${ }^{23}$

N'Diaye et al. ${ }^{13}$

Gallant et al. ${ }^{24}$

Ditkowsky and Schwartzman ${ }^{25}$

Tiemersma et al. ${ }^{26}$

Tiemersma et al. ${ }^{26}$

Tan et al. ${ }^{20}$

Smith et al. ${ }^{21}$

Khan et al., ${ }^{8}$ Inuit Tapiriit Kanatami ${ }^{19}$

NRBHSS ${ }^{18}$

Institut de la statistique du Québec, ${ }^{16}$

Institut de la statistique du Québec, ${ }^{16}$ Inuit Tapiriit Kanatami ${ }^{19}$

NRBHSS ${ }^{18}$

NRBHSS 18

Note: $\mathrm{LTBI}=$ latent tuberculosis infection, NRBHSS $=$ Nunavik Regional Board of Health and Social Services, $\mathrm{TB}=$ tuberculosis.

* Standard TB management in the region requires all persons with active pulmonary TB to be admitted to hospital. ${ }^{18}$

†These cascade parameters are specific to Village 1. Those pertaining to Village 2 are provided in Appendix 1, Supplementary Table S2, available at www.cmaj.ca/lookup/doi/10.1503/ cmaj.210447/tab-related-content.

tThe probabilities of progression and reactivation changed over time in the model, starting at their high values $(0.265$ and 0.075 , respectively) and declining over time. This reflected the presence of an outbreak at the beginning of the model, with a subsequent decline in transmission. In scenarios where repeated outbreaks were simulated, we adjusted these parameters accordingly (in addition to the annual risk of infection parameter). This process is described in detail in the Simulating outbreaks section of Appendix 1.

$\S$ These values change year over year in the model to reflect changing birth and death rates in the region.

IThe value of these cascade parameters increases when active screening is added.

rates of $L T B I$ treatment initiation and completion, decreased rates of LTBI diagnosis, use of local staff (to decrease lodging and transportation costs), reduced adherence to active screening and variations in outbreak intensity. Varying outbreak intensity involved lower peaks for the progression and reactivation parameters during outbreaks. Detailed descriptions are available in the Incorporation of additional strategies and Scenario analyses sections in Appendix 1.

Finally, we used one-way sensitivity analyses and probabilistic sensitivity analysis to assess the impact of variation in input parameters on predicted outcomes. The probabilistic sensitivity analysis involved 10000 model runs and sampled parameters from prespecified ranges (listed in Appendix 1, Supplementary Table S1).

\section{Ethics approval}

Because the analysis was initiated by the NRBHSS and used only aggregate program data, ethics review board approval was not required. However, results were first shared with community members of the NRBHSS, and community leaders' and members' approval of this manuscript was obtained before submission.

\section{Results}

The 2019 active screening campaigns took place in the 2 villages over 6-11 weeks. They found 52 people with previously unknown LTBI and 13 with previously undiagnosed active TB. ${ }^{22}$ For simplicity, we focus on results for Village 1, which had more extensive outbreaks. 
Table 2: Key cost parameters used in the decision analysis model

\section{Parameter}

\section{Cost related to active screening*}

Total cost of active screening per person (in 2019†)

a) Total cost of human resources

b) Total cost of lodging and transport

c) Total cost of communication and mobilization

d) Total cost of training and workshops

e) Total cost of supplies

f) Total cost of amenities

\section{Cost related to management of active TB and LTBI}

Cost of medication for active TB

Cost of medication for latent TB

Cost of visits to manage active TB treatment

Cost of visits to manage LTBI treatment

Cost of severe adverse event caused by active TB treatment

Cost of adverse event during LTBI treatment

Cost of medical evacuation

Cost of hospital stay per day

Value, 2019 Can\$

Source

$\begin{array}{cc}1952 & \text { NRBHSS }^{22} \\ 776 & \text { NRBHSS }^{22} \\ 1102 & \text { NRBHSS }^{22} \\ 5 & \text { NRBHSS }^{22} \\ 2 & \text { NRBHSS }^{22} \\ 49 & \text { NRBHSS }^{22} \\ 18 & \text { NRBHSS }^{22}\end{array}$

674

114

436

42

16364

782

6713

2050
RAMQ $^{28}$

RAMQ $^{28}$

FIQ, ${ }^{29}$ Alsdurf et al. ${ }^{30}$

FIQ, ${ }^{29}$ Alsdurf et al., ${ }^{30}$

Campbell et al. ${ }^{31}$

Tan et al. ${ }^{20}$

Campbell et al. ${ }^{31}$

Banerji et al. ${ }^{32}$

$\mathrm{NRBHSS}^{33}$

Note: FIQ = Fédération Interprofessionelle de la santé du Québec, LTBI = latent tuberculosis infection, NRBHSS = Nunavik Regional Board of Health and Social Services, RAMQ = Régie de l'assurance maladie du Québec, TB = tuberculosis.

*These costs are specific to Village 1 (there were 604 people screened in Village 1). Costs pertaining to Village 2 are provided in Appendix 1, Supplementary Table S1, available at www. cmaj.ca/lookup/doi/10.1503/cmaj.210447/tab-related-content.

†Construction costs are included in the lodging and transport costs. The village required an extra structure to be built to accommodate screening activities, which is what comprises the construction costs. In subsequent years, if active screening was repeated, we removed costs related to construction so the cost of active screening per person was cheaper. The

total cost of active screening is equal to the sum of $a, b, c, d$, e and $f$

\section{Given a single outbreak in 2019}

Results are summarized in Table 3, with strategies ordered from least to most expensive. Compared with no active screening, adding community-wide active screening in 2019 was estimated to reduce the number of people with active TB by $13 \%$ (95\% uncertainty range $-3 \%$ to $27 \%$ ) over 20 years, and was less expensive (dominant), saving \$355 (95\% uncertainty range - \$273 to \$1055) per person.

\section{Given an outbreak in 2019 and every 3 years thereafter}

The results for Strategies A, B and C, in the presence of an outbreak every 3 years, are shown in Table 4 and Table 5. Compared with no active screening, Strategies $B$ and $C$ substantially reduced the number of active TB cases. Strategy C, in which community-wide active screening occurs every 2 years from 2019 to 2039, had the largest impact on TB morbidity and mortality, reducing active TB cases by $63 \%$ (95\% uncertainty range $57 \%$ to $67 \%$ ) compared with Strategy A. Strategies B and C were cost saving compared with Strategy A.

Compared with no active screening, Strategies B and C were both dominant. Strategy $C$ was more effective but likely more expensive than Strategy B.

\section{Village 2}

In Village 2, active screening in 2019 alone was reasonably costeffective ( $\$ 22134$ per active TB case averted) but not cost saving compared with no active screening. Biennial active screening also was reasonably cost-effective, given outbreaks every 3 years (\$22292 per active TB case averted), compared with no active screening. However, 95\% uncertainty ranges were wide. Detailed results are provided in Appendix 1, Supplementary Tables S4-S7.

\section{Scenario analyses}

With a strengthened LTBI cascade, a single round of active screening remained cost saving compared with no active screening in the presence of a single outbreak and in the presence of an outbreak every 3 years. Biennial active screening, however, was no longer cost saving in the presence of an outbreak every 3 years; the incremental cost per person, compared with no screening, was $\$ 392$ (95\% uncertainty range $-\$ 2584$ to $\$ 5297$ ).

When the intensity of future outbreaks was reduced by $25 \%$ (peaks in progression and reactivation parameters reduced by $25 \%)$, Strategy B remained cost saving compared with Strategy $A$, but Strategy $C$ became more expensive than Strategy $A$. The incremental cost per person of biennial active screening, compared with no active screening, was $\$ 577$ (95\% uncertainty range $-\$ 2825$ to $\$ 5981)$. The same pattern was observed when the intensity of future outbreaks was reduced to a greater degree (see Appendix 1, Supplementary Table S8 and Supplementary Figures S1 and S2 for further details on all scenario analyses). 
Table 3: Outcomes over 20 years in Village 1, given a single outbreak in 2019

No. of cases ( $95 \%$ uncertainty range)

\begin{tabular}{ll} 
Strategy* & Cost, \$ (95\% uncertainty range) \\
\hline B & 6996027 (5647525 to 8975360$)$ \\
\hline A & $7493340(5927277$ to 9748954$)$
\end{tabular}

$\begin{array}{cc}\text { Incident active TB† } & \text { Incident LTBI† } \\ 90 \text { (79 to } 103) & 38 \text { (33 to } 45) \\ 103 \text { (90 to } 118) & 42(36 \text { to } 48)\end{array}$

No. ( $95 \%$ uncertainty range) of TB-related deaths

0.6 (0.4 to 0.7$)$

$0.9(0.7$ to 1.0$)$

Note: $\mathrm{LTBI}=$ latent tuberculosis infection, TB = tuberculosis.

*Strategy A: no active screening. Strategy B: community-wide active screening in 2019.

tIncident LTBI includes new infections and reinfections. Incident active TB similarly includes cases due to primary progression or reactivation, as well as relapse. Both incident LTBI and incident active TB include secondary infections and active TB cases. Results in Appendix 1 (available at www.cmaj.ca/lookup/doi/10.1503/cmaj.210447/tab-related-content) present secondary infections and secondary active TB cases separately.

\section{Table 4: Outcomes over 20 years in Village 1 given an outbreak every 3 years, starting in 2019}

\begin{tabular}{|c|c|c|c|c|}
\hline Strategy* & Cost, \$ & $\begin{array}{l}\text { No. ( } 95 \% \text { uncertainty range) } \\
\text { of cases of incident active TB } \dagger\end{array}$ & $\begin{array}{c}\text { No. (95\% uncertainty } \\
\text { range) of cases of incident } \\
\text { LTBI† }\end{array}$ & $\begin{array}{l}\text { No. (95\% uncertainty } \\
\text { range) of TB-related } \\
\text { deaths }\end{array}$ \\
\hline B & 14745984 (11715969 to 18606081$)$ & 249 (227 to 266$)$ & 87 (83 to 94) & 1.5 (1.2 to 1.8$)$ \\
\hline C & 15691149 (13059608 to 18908752$)$ & $102(90$ to 117$)$ & 30 (28 to 35$)$ & $0.3(0.2$ to 0.3$)$ \\
\hline A & 16359259 (12846266 to 20772912 ) & 276 (252 to 294$)$ & 94 (89 to 101$)$ & 1.9 (1.6 to 2.3$)$ \\
\hline
\end{tabular}

Table 5: Incremental cost per case of active tuberculosis averted in Village 1, given an outbreak every 3 years, starting in 2019

$\begin{array}{cc}\text { Incremental cost per person compared } \\ \text { with preceding strategy, } \\ \text { Strategy* } & \$(95 \% \text { uncertainty range })\end{array}$

Incremental cost per active TB case averted $\dagger$ compared with preceding strategy, \$ (95\% uncertainty range)

Incremental cost per active TB case averted compared with Strategy A

B

C 674 (-1427 to 2808)

A $\quad 477$ (-1827 to 2865$)$
$6430(-29131$ to 13658$)$

Dominated $\dagger$
Dominant $\ddagger$

Dominantł

Note: TB = tuberculosis.

*Strategy A: no active screening. Strategy B: community-wide active screening in 2019. Strategy C: community-wide active screening every 2 years from 2019 to 2039.

tIncremental cost per active TB case averted is the difference in costs divided by the difference in active TB cases between 2 strategies. The population of Village 1 at the end of the simulation was 1402 .

‡Because Strategies B and C were less costly and more effective than Strategy A at averting active TB cases, we considered them to be "dominant", therefore, Strategy A was dominated.

\section{Sensitivity analyses}

We found that one-way sensitivity analysis suggested that per diem costs of hospital admission for active TB, duration of hospital admission if smear positive, the probability of progression to active TB and the probability of cure following incomplete LTBI treatment were the most influential drivers of cost-effectiveness. We also found that variations in these parameters changed the incremental savings per active TB case averted but did not change conclusions (Appendix 1, Supplementary Figures S3-S6).

We used probabilistic sensitivity analyses to derive the 95\% uncertainty ranges in the previously mentioned tables; these analyses are shown in Appendix 1, Supplementary Figures S7-S10. These analyses showed that, with a single outbreak, active screening averted more active TB cases than no active screening in $94 \%$ of simulations for Village 1 . Active screening was cost saving (as well as effective) in $86 \%$ of simulations. Therefore, active screening was the dominant strategy in most simulations. With outbreaks every 3 years, biennial active screening was more effective (and more expensive) than a single round of screening in $75 \%$ of simulations. We determined that biennial active screening averted more TB disease than no active screening and one-time screening in all simulations. 


\section{Interpretation}

In Inuit communities with high TB incidence, we found that active screening is likely to be reasonably cost-effective and potentially cost saving. Historically, community-wide screening has been implemented after outbreaks. The ideal screening program will prevent future outbreaks, but it is impossible to predict exactly when an outbreak will occur. The high cost of care for TB in Canada's North makes preventive interventions more costeffective. Although there is no absolute threshold that defines cost-effectiveness in terms of cost per TB case averted, we projected active screening to be cost saving compared with no active screening in Village 1, given repeated large outbreaks. In Village 2 , active screening was likely cost-effective but not cost saving, which reflected a lower TB burden and screening yield (the 2019 screening campaign detected fewer people with active TB than in Village 1, despite having a larger population).

The Inuit Tuberculosis Elimination Framework highlights key knowledge gaps with respect to active screening. ${ }^{3}$ Our study builds on previous work from Nunavut and Nunavik ${ }^{15,34}$ by projecting potential costs and cost savings, as well as health benefits. Emerging literature suggests that active TB screening in such diverse settings as Cambodia, India, China, South Africa, Pakistan and the South Pacific is effective and cost-effective - particularly if repeated over the longer term. ${ }^{12,35-37}$

It is essential that all TB care and prevention activities engage and mobilize communities in a culturally safe and appropriate manner. To that end, the NRBHSS has partnered with communities to develop and implement a regional plan for TB elimination, within the TB Elimination Framework created by Inuit Tapiriit Kanatami. This framework acknowledges the importance of strengthening local capacity and of the social determinants of health, including housing and food security. ${ }^{2,3}$ We focused on community-wide screening as a stand-alone intervention; we did not address these fundamental upstream determinants herein, but previous publications have explored them in the Nunavut context. ${ }^{13,14}$

\section{Limitations}

We made several key assumptions. We assumed that costs related to construction would not recur and that only operational costs would recur. We initially assumed that adherence to repeated cycles of community-wide screening was 100\%, although this was varied in scenario analysis. We also assumed that people with LTBI who were identified by community screening would not otherwise have been found, and people with active TB who were found by active screening would have otherwise been diagnosed at a later, more infectious stage. In addition, the model was not stratified by age, so we could not assess whether benefits of active screening were higher in specific age groups - recognizing that the average age in Inuit communities is much younger than in Southern Canada. ${ }^{19}$

Another limitation was the lack of region-specific data for certain model parameters. Wherever possible, we then used data from other Inuit regions. This was the case for estimating secondary transmission, for which we used both program and published data. When such data were not available, we used data from other settings (for the probability of treatment toxicity, for example), whereas epidemiologic parameters were vetted by the local public health authority.

\section{Conclusion}

Tuberculosis continues to exact a large and disproportionate burden on many Inuit communities across Canada's North. We anticipate that community-based screening, supported by prompt and effective treatment of both active TB disease and latent infection, can play an important role in communities with the highest incidence.

\section{References}

1. Global tuberculosis report 2020. Geneva: World Health Organization; 2020.

2. Cormier M, Schwartzman K, N'Diaye DS, et al. Proximate determinants of tuberculosis in Indigenous peoples worldwide: a systematic review. Lancet Glob Health 2019;7:e68-80.

3. Inuit Tuberculosis Elimination Framework. Canada: Inuit Tapiriit Kanatami; 2018.

4. High burden TB countries - 2021 update. TBFacts.org: information about tuberculosis; 2021. Available: https://tbfacts.org/high-burden-tb/ (accessed 2021 June 15).

5. LaFreniere M, Hussain H, He N, et al. Tuberculosis in Canada: 2017. Can Commun Dis Rep 2019;45:67-74.

6. Notifiable diseases (MADO) and public health reports. Quebec: Ministère de la Santé et des Services sociaux du Québec; data extracted 2021 Jan. 28.

7. Gale-Rowe M, Menzies D, Sutherland J, et al. Tuberculosis: highlights of the new 7th edition of the Canadian Tuberculosis Standards. Can Commun Dis Rep 2014;40:113-6.

8. Khan FA, Fox GJ, Lee RS, et al. Housing and tuberculosis in an Inuit village in northern Quebec: a case-control study. CMAJ Open 2016;4:E496-E506.

9. Systematic screening for active tuberculosis: principles and recommendations. Geneva: World Health Organization; 2013.

10. Kranzer K, Afnan-Holmes H, Tomlin K, et al. The benefits to communities and individuals of screening for active tuberculosis disease: a systematic review. Int J Tuberc Lung Dis 2013;17:432-46.

11. Rose DN. Benefits of screening for latent Mycobacterium tuberculosis infection. Arch Intern Med 2000;160:1513-21.

12. Hill PC, Dye C, Viney K, et al. Mass treatment to eliminate tuberculosis from an island population. Int J Tuberc Lung Dis 2014;18:899-904.

13. N'Diaye DS, Nsengiyumva NP, Uppal A, et al. The potential impact and costeffectiveness of tobacco reduction strategies for tuberculosis prevention in Canadian Inuit communities. BMC Med 2019;17:26.

14. Uppal A, Oxlade O, Nsengiyumva NP, et al. Social and behavioral risk reduction strategies for tuberculosis prevention in Canadian Inuit communities: a costeffectiveness analysis. BMC Public Health 2021;21:280.

15. Dion R, Brisson M, Proulx JF, et al. Results of a population screening intervention for tuberculosis in a Nunavik village, Quebec, 2015-2016. Can Commun Dis Rep 2018;44:257-63.

16. Births, deaths, natural increase and marriages, administrative regions, Québec, 1986-2020 [article in French]. Québec: Institut de la statistique du Québec; 2021. Available: https://statistique.quebec.ca/en/produit/tableau/births-deaths -natura-increase-and-marriages-administrative-regions-quebec (accessed 2021 June 15).

17. Guidelines for the economic evaluation of health technologies. Ottawa: Canadian Agency for Drugs and Technologies in Health; 2021. Available: https://cadth.ca/ guidelines-economic-evaluation-health-technologies-canada-0 (accessed 2021 June 18).

18. Regional tuberculosis data. Kuujjuaq (QC): Nunavik Regional Board of Health and Social Services; 2019.

19. 2018 Inuit statistical profile. Ottawa: Inuit Tapiriit Kanatami; 2018.

20. Tan M, Menzies D, Schwartzman K. Tuberculosis screening of travelers to higherincidence countries: a cost-effectiveness analysis. BMC Public Health 2008;8:201.

21. Smith BM, Schwartzman K, Bartlett G, et al. Adverse events associated with treatment of latent tuberculosis in the general population. CMAJ 2011;183:E173-9. 
22. Program data from active screening initiatives. Kuujjuaq (QC): Nunavik Regional Board of Health and Social Services; 2019.

23. Behr MA, Edelstein PH, Ramakrishnan L. Revisiting the timetable of tuberculosis. BMJ 2018;362:k2738.

24. Gallant V, Duvvuri V, McGuire M. Tuberculosis (TB): tuberculosis in Canada summary 2015. Can Commun Dis Rep 2017;43:77-82.

25. Ditkowsky JB, Schwartzman K. Potential cost-effectiveness of a new infant tuberculosis vaccine in South Africa--implications for clinical trials: a decision analysis. PLoS One 2014;9:e83526.

26. Tiemersma EW, van der Werf MJ, Borgdorff MW, et al. Natural history of tuberculosis: duration and fatality of untreated pulmonary tuberculosis in HIV negative patients: a systematic review. PLoS One 2011;6:e17601.

27. Inflation calculator. Ottawa: Bank of Canada. Available: https://www.bankofcanada .ca/rates/related/inflation-calculator/ (accessed 2020 Nov. 4).

28. List of medications. Quebéc: Regie de l'assurance maladie du Québec; 2020.

29. Salary scales and list of job titles: collective agreement. Montréal: Fédération Interprofessionelle de la santé du Québec; 2020. Available: fiqsante.qc.ca (accessed 2020 Nov. 14).

30. Alsdurf H, Oxlade O, Adjobimey M, et al. Resource implications of the latent tuberculosis cascade of care: a time and motion study in five countries. BMC Health Serv Res 2020;20:341.
31. Campbell JR, Johnston JC, Cook VJ, et al. Cost-effectiveness of latent tuberculosis infection screening before immigration to low-incidence countries. Emerg Infect Dis 2019;25:661-71.

32. Banerji A, Panzov V, Robinson J, et al. The cost of lower respiratory tract infections hospital admissions in the Canadian Arctic. Int J Circumpolar Health 2013;72: doi: 10.3402/ijch.v72i0.21595.

33. Fees from regional hospital. Nunavik: Nunavik Regional Board of Health and Social Services; 2020.

34. Alvarez GG, VanDyk DD, Aaron SD, et al. Taima (stop) TB: the impact of a multifaceted TB awareness and door-to-door campaign in residential areas of high risk for TB in Iqaluit, Nunavut. PLoS One 2014;9:e100975.

35. Azman AS, Golub JE, Dowdy DW. How much is tuberculosis screening worth? Estimating the value of active case finding for tuberculosis in South Africa, China, and India. BMC Med 2014;12:216.

36. Hussain H, Mori AT, Khan AJ, et al. The cost-effectiveness of incentive-based active case finding for tuberculosis (TB) control in the private sector Karachi, Pakistan. BMC Health Serv Res 2019;19:690.

37. Yadav RP, Nishikiori N, Satha P, et al. Cost-effectiveness of a tuberculosis active case finding program targeting household and neighborhood contacts in Cambodia. Am J Trop Med Hyg 2014;90:866-72.

\section{Competing interests: None declared.}

This article has been peer reviewed.

Affiliations: Montreal Chest Institute (Uppal, Khan, Schwartzman); Respiratory Epidemiology and Clinical Research Unit, Centre for Outcomes Research and Evaluation (Uppal, Nsengiyumva, Khan, Schwartzman), Research Institute of McGill University Health Centre; McGill International Tuberculosis Centre (Uppal, Nsengiyumva, Khan, Schwartzman), Montréal, Que.; Régie régionale de la santé et des services sociaux du Nunavik (Signor, Jean-Louis, Rochette); Kativik Regional Government (Snowball); Ulluriaq School (Etok), Kangiqsualujjuaq; Northern Village of Kangiqsualujjuaq (Annanack); Salluit Birth Center, Salluit (Ikey), Québec, Que.

Contributors: Kevin Schwartzman, Faiz Ahmad Khan and Frantz JeanLouis contributed to concept and design. Aashna Uppal and Kevin Schwartzman drafted the manuscript. Aashna Uppal, Ntwali Placide Nsengiyumva, Céline Signor, Frantz Jean-Louis, Faiz Ahmad Khan and Kevin Schwartzman performed the statistical analysis. All of the authors acquired, analyzed and interpreted the data; critically revised the manuscript for important intellectual content; gave final approval of the version to be published; and agreed to be accountable for all aspects of the work.

Content licence: This is an Open Access article distributed in accordance with the terms of the Creative Commons Attribution (CC BY-NC-ND 4.0) licence, which permits use, distribution and reproduction in any medium, provided that the original publication is properly cited, the use is noncommercial (i.e., research or educational use), and no modifications or adaptations are made. See: https://creativecommons.org/licenses/ by-nc-nd/4.0/

Funding: This work was funded by the Régie régionale de la santé et des services sociaux du Nunavik, Quebec. The funder itself had no role in the design, conduction, data collection, analysis, management, interpretation, or in manuscript preparation or in the decision to submit for publication. However, professional and community members of the Régie régionale de la santé et des services sociaux du Nunavik were authors and reviewed and approved the final manuscript accordingly.

Data-sharing: The authors confirm that the most relevant data are provided in the main text or Appendix 1. In addition, there is a publicly available summary of epidemiologic data related to the screening programs (https://bc.lung.ca/sites/default/files/Jean\%20Louis.pdf) and the decision analysis model has been posted online (https://www.mcgill.ca/ $\mathrm{tb} /$ projects). Both the summary and the model protect the identity of the 2 villages considered in the study. Some specific data pertaining to the financial details of the screening campaigns have been withheld to maintain confidentiality of those involved. However, additional information may be made available upon reasonable request to the corresponding author.

\section{Accepted: Sept. 14, 2021}

Correspondence to: Kevin Schwartzman, kevin.schwartzman@mcgill.ca 